\title{
VARIA
}

\section{LOS MESÍAS DE QUMRÁN. PROBLEMAS DE UN TRADUCTOR *}

En Textos de Qumran ' he intentado presentar una traducción lo más fiel posible de los fragmentos recuperados en esa biblioteca portentosa a la que debemos lo mejor de nuestro conocimiento del judaísmo del Segundo Templo. Pero la tarea de un traductor esta llena de escollos que procura resolver lo mejor que puede. Lo que al final del trayecto ofrece a sus lectores no es más que el resultado de un largo proceso y de una serie múltiple de opciones. El lector sólo recibe el resultado final. Y puesto que en la mayoría de los casos no está en condiciones de verificar el trabajo del traductor, no puede controlar lo bien fundado de las opciones que el traductor ha hecho. Por eso quisiera mostrarles aquí, con la ayuda de algunos ejemplos concretos, el proceso que me ha llevado a determinadas traducciones, explicar el porqué, justificando así las opciones hechas. $Y$ puesto que toda traducción (además de traición, ya que el trasvase perfecto de contenidos de un universo lingüístico a otro es siempre imposible) es interpretación, la explicación de mis opciones es al mismo tiempo la justificación de mi interpretación de los textos en cuestión.

He escogido para ellos tres textos que me parecen significativos por su contenido teológico (se trata de textos claramente mesiáni$\cos ^{2}$ ) y porque cada uno de ellos representa uno de los tipos de opciones que un traductor de manuscritos mal conservados y fragmentarios, como son los textos de Qumrán, está obligado a hacer continuamente:

* Texto de la conferencia leída en el Instituto de Filología del Consejo Superior de la Investigaciones Científicas de Madrid el 22 de abril de 1993. He conservado el carácter de comunicación oral, limitándome a añadir las notas indispensables. Quiero agradecer a los participantes en el acto las aportaciones hechas durante la animada discusión que siguió a la lectura.

' F. García Martínez, Textos de Qumrán, Madrid 1992.

${ }^{2}$ Que he estudiado con mayor detalle en una contribución que será publicada en alemán en el Jahrbuch für Biblische Theologie 8 (1993). 
1) opciones de lectura del texto consonántico, debidas a la dificultad de descifrar las fotografías cuando la escritura no es clara y los signos pueden interpretarse de distintas maneras. El ejemplo proviene de 4 Q521;

2) opciones de interpretación del sentido de una palabra o de una frase de lectura clara pero cuyo esqueleto consonántico puede ser comprendido de diversas maneras, todas ellas gramaticalmente posibles. El ejemplo escogido es el fragmento 5 de 4Q285;

3) opciones de comprensión del sentido general de un texto de lectura segura, sin problemas gramaticales, pero abierto a múltiples significados que únicamente el contexto literario puede ayudar a resolver. El ejemplo lo proporcionará 4Q246.

Pero antes de afrontar directamente estos textos, y puesto que se trata de textos mesiánicos, es necesario recordar brevemente los elementos de sobra conocidos del "mesianismo" del Antiguo Testamento, la fuente de la que manan los textos de Qumrán y que nos proporciona el contexto literario en el que deben ser interpretados.

En el Antiguo Testamento no hay Mesías. Hay indicios, rastreos, gérmenes de ideas que en épocas posteriores se plasmarán en la idea del "Mesías". En ninguna de las 39 ocasiones en las que en la Biblia hebrea se emplea la palabra masiah ('ungido'), tiene esta palabra el sentido técnico preciso de título de la figura escatológica cuya venida introducirá la era de la salvación. En palabras de F. Hesse "Keine der Messias-Stellen des Alten Testaments kann messianisch gedeutet werden" 3. Los Mesías del Antiguo Testamento son figuras del presente, generalmente el rey (en Is 54,1 se trata de Ciro); más raramente, sacerdotes, patriarcas o profetas; y en los dos casos en los que Daniel emplea la palabra, dos personajes cuya identidad es difícil de precisar pero que ciertamente no son figuras "mesiánicas". La tradición posterior reinterpretará ciertamente varias de estas alusiones veterotestamentarias al Mesías como predicciones mesiánicas, pero las raíces de las concepciones que posteriormente emplearán el título de Mesías para designar a las figuras que introducirán la salvación escatológica se hallan en otros textos del AT que no emplean la palabra masiah h. Textos como las bendiciones de Jacob (Gen 49,10), el oráculo de Balaam (Num 24,17), la profecía de Natán (2 Sam 7) y los Salmos reales (como Sal 2 y 110) serán desarrollados por Isaías, Jeremías y Ezequiel en dirección a la espera de un futuro Mesías real,

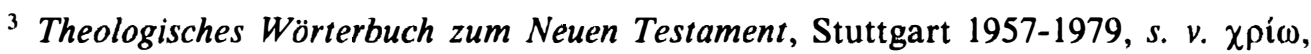
$\kappa \tau \lambda .$, pág. 494. 
heredero del trono de David. Las promesas de restauración del sacerdocio en algunos textos como Jer 33,14-26 (ausente en los LXX) y el oráculo sobre el sumo sacerdote Josué recogido en Zac 3, servirán de punto de arranque de la esperanza posterior de un Mesías sacerdotal, lo mismo que la doble investidura de los «hijos del aceite», Zerubabel y Josué, en Zac 6,9-14, será el punto de partida de la espera de un doble Mesías, reflejo de una cierta división de poderes, presente ya desde Moisés y Aarón. De la misma manera, la presencia de la triple función: rey, sacerdote, profeta, unida al anuncio de la futura venida de un "profeta como Moisés" de Deut $18,15.18$ y a la esperanza concreta del retorno de Elías de Mal 3,23, servirá de punto de arranque para el desarrollo de la esperanza en la venida de un agente de salvación escatológico, se le designe o no como Mesías. Igualmente, la presentación de la misteriosa figura del "siervo de YHWH" de los caps. 40-55 de Isaías como una alternativa al mesianismo tradicional en la perspectiva de la restauración dará como resultado el desarrollo de la esperanza de un "Mesías sufriente», y el anuncio de Mal 3,1 de que Dios ha de enviar a su «ángel» como mensajero para preparar su venida permitirá desarrollar la espera de un mediador escatológico de origen no terrestre.

En estos y en otros textos del Antiguo Testamento se halla la semilla del mesianismo posterior. Pero hasta ahora no podíamos ver cómo esta semilla había germinado y dado fruto, ni cómo en ese siglo primero de la era que llamamos "cristiana" (es decir, del "ungido", del "mesías"), esos gérmenes de esperanza mesiánica se habían transformado en un bosque de figuras mediadoras que al final de los tiempos introducen como heraldos y agentes eficaces la salvación de Dios. Y es precisamente esto lo que nos brindan los manuscritos de Qumrán. Todo el complejo de esperanzas mesiánicas tan diversas, apenas apuntadas en la Biblia hebrea, se hallan recogidas y desarrolladas dentro de los textos de Qumrán.

Después de haber refrescado así la memoria, podemos pasar a analizar los textos.

1. $4 \mathrm{Q} 521$

Podemos comenzar con $4 \mathrm{Q} 521$, un texto recientemente publicado por E. Puech ${ }^{4}$. Es un texto fascinante, aunque su interpretación no

${ }^{4}$ E. Puech, “Une apocalypse messianique (4Q521)”, $R Q 15 / 60$ (1992) 475-522. 
deja de presentar problemas. El manuscrito había sido descrito con una gran precisión por J. Starcky en 1956: “Un beau texte mentionne le Messie, mais les bienfaits du salut eschatologique, évoqués d'après Is XLss et Ps CXLVI, sont attribués directement à Adonai» 5. La referencia al Mesías aparece en el fragmento 2, el fragmento mejor conservado:

1 [pues los cie]los y la tierra escucharán a su mesías, ${ }^{2}$ [y todo] lo que hay en ellos no se apartará de los preceptos de los santos. ${ }^{3}$ ¡Reforzáos, los que buscáis al Señor en su servicio! Vacat. ${ }^{4}$ ¿Acaso no encontraréis en eso al Señor, (vosotros,) todos los que esperan en su corazón? ${ }^{5}$ Porque el Señor observará a los piadosos, y llamará por el nombre a los justos, ${ }^{6}$ y sobre los pobres posará su espíritu, y a los fieles los renovará con su fuerza. ${ }^{7}$ Pues honrará a los piadosos sobre el trono de la realeza eterna, ${ }^{8}$ librando a los prisioneros, dando la vista a los ciegos, enderezando a los torcidos. 9 Por siempre me adheriré a los que esperan. En su misericordia él juz[gará] ${ }^{10} \mathrm{y}$ a nadie le será retrasado el fruto [de la obra] buena, ${ }^{11} \mathrm{y}$ el Señor obrará acciones gloriosas como no han existido, como él lo ha di[cho, ${ }^{12}$ pues curará a los malheridos, y a los muertos los hará vivir, anunciará buenas noticias a los humildes, ${ }^{13}$ colmará [a los indigen]tes, conducirá a los expulsados, y a los hambrientos los enriquecerá. ${ }^{14}[\ldots]$ y todos [...] (4Q521 fragm. 2 col. II) ${ }^{6}$.

El único estudio aparecido hasta el momento sobre este manuscrito ${ }^{7}$ considera que nuestro texto habla efectivamente del Mesías davídico, pero sin aportar ningún otro argumento que la aserción (claramente errónea) de que en Qumrán (con la posible excepción de 1QS) solamente se esperaba a un Mesías. Para los autores, el personaje descrito en $4 \mathrm{Q} 521$ sería el precedente directo de la concepción cristiana del Mesías ${ }^{*}$. Su argumento es doble: 1) la suposición

5 J. STARCKY, «Le travail d'édition des manuscrits de Qumrân» RB 63 (1956) 49-67, 66.

${ }^{\circ}$ Cf. F. García Martínez, Textos de Qumrán, págs. 409-410.

7 O. WisE - J. D. TABOR, "The Messiah at Qumran", BAR 18/6 (1992) 60-65.

8 "In contrast, the Messiah of our text, 4Q521, controls heaven and earth, heals the wounded and raises the dead. He rules over nature. Even death, the old enemy, cannot stand before him (he will resurrect the dead). Christians embraced a similarly exalted view of their Messiah as one who ruled over heaven and earth». Ibid., pág. 61 . 
de que 4Q521 presenta al Mesías resucitando a los muertos ${ }^{9}$, y 2) el paralelo de las expresiones de la línea 12 con Mat 11,4-5 y Luc 7,22$23^{10}$, respuesta a la embajada del Bautista, en la que son descritos los signos de la llegada del Mesías. Esta segunda constatación es correcta, en cuanto que la unión en una misma frase de la resurrección de los muertos con el anuncio de buenas nuevas a los canawîm proveniente de Is 61,1 no estaba atestiguada precedentemente fuera del Nuevo Testamento. Pero la primera suposición, que ve al Mesías como el agente de las acciones portentosas de la salvación escatológica, me parece completamente equivocada y no es más que el resultado de una lectura defectuosa del manuscrito. Y éste es el motivo por el que he escogido este texto como ilustración de la primera de las opciones que un traductor deber hacer: una opción de lectura.

En la lín. 10 O. Wise y J. D. Tabor leen וט[ובו לעד. משיחו] הקדש ... לוא, apoyando su reconstrucción en el empleo de esta misma הקדש como la de וט]ובו com la son paleográficamente imposibles; el peh leído por Puech es cierto, y es imposible, ya que, en ese caso, al menos la parte inferior del qof debería ser visible en la fotografía. Esta línea debe leerse, con el editor ... ופר]י מעש][ה טוב לאיש לוא.

Aún más grave e igualmente falsa es su lectura מעשה, en la línea 11, que, además de ser sintácticamente extraña, priva de sujeto a los verbos siguientes. En el manuscrito la primera letra no es del todo clara, y además lleva debajo un punto negro, parecido a los que a veces los escribas qumránicos emplean para cancelar una letra erróneamente escrita, pero que puede ser completamente accidental. Lo que sí aparece claramente en un examen detallado de la fotografía es que el mem es imposible, y que la primera letra es muy probablemente un yod, lo que lleva a optar por una lectura ivis.

Wise y Tabor se ven obligados a reconocer que el Señor es el agente de las obras anunciadas en las líneas 5-9 (entre las que se

${ }^{9}$ "In our Dead Sea Scroll text, the author presumably would have agreed that power over life and death ultimately comes from God, but he would insert God's Messiah as the mediator of resurrection. Here the Dead Sea Scroll text stands with earliest Christianity, rather than what emerged as rabbinic Judaism". Ibid., pág. 65.

10 "The line of our text (line 12) relating to the resurrection of the dead is remarkable for another reason: It contains one of the closest, most direct linguistic parallels to a New Testament text that has ever been discovered in the scrolls". Ibid., pág. 65. 
encuentran algunos de los elementos, como la curación de los ciegos, que también aparecen en los textos neotestamentarios), pero suponen un cambio de sujeto a partir de la línea 10. Una vez que han optado por leer מעשה en la línea 11, se ven obligados a interpretar el Adonay siguiente como dependiendo de esta palabra, con lo que la línea se les queda sin sujeto gramatical. Para suplirlo introducen en la laguna de la línea 10 (como hemos visto) una mención del Mesías ". El resultado es la introducción en el texto de una idea que no sólo no aparece si el texto es correctamente leído, sino que es contraria al pensamiento de toda la Biblia hebrea: la idea de que hay acciones maravillosas (en sentido positivo) que no son obra del Señor. Wise y Tabor traducen así las líneas en cuestión:

"(10) a[nd in His] go[odness forever. His] holy [Messiah] will not be slow [in coming.] (11) And as for the wonders that were not the work of the Lord, when he (i.e. the Messiah) [come]s (12) then he will heal the sick, resurrect the dead, and to the poor announce glad things».

Pero todas estas especulaciones son innecesarias si el texto es correctamente leído: «El Señor obrará acciones gloriosas que no han existido". En el texto, como yo lo he leído, ni el Mesías resucita a los muertos, ni hay acciones maravillosas que no son obra de Dios. Lo que el texto nos enseña es que en la época final, en el tiempo del Mesías, Dios obrará acciones maravillosas como lo ha prometido, y que la resurrección de los muertos (de los que han sido fieles, por supuesto ${ }^{12}$ ) será una de estas obras maravillosas.

Incidentalmente, este mismo texto podría servirnos también como ejemplo de la segunda categoría de opciones que un traductor está obligado a hacer. El texto hebreo lee claramente למשיחו en la primera línea, pero como señala el editor, en el hebreo de Qumrán, la forma puede también ser leída como un plural (y de hecho un buen número de autores traducen en plural "sus ungidos" משיחו de CD II 12 y VI 1 sin corregirlo en משיחי), por lo que Puech traduce prudentemente: «Son (/Ses?) Messie(s)». Es decir, que el texto en sí

11 Aunque reconocen: "This is a crucial and straightforwardly speculative restoration". Ibid., pág. 63.

12 Como lo precisa el fragm. 7 + 5 II 5-6: "como ellos los malditos; pues ellos serán para la muerte [cuando] (6) [haga al]zarse el vivificador a los muertos de su pueblo". 
puede interpretarse como tratando de un Mesías o de varios Mesías. Si yo he optado claramente por una traducción en singular (a pesar de la escritura defectiva del plural ממצות) se debe a la presencia en el fragm. 8,9 de משיחיה, que es claramente plural ${ }^{13}$ y que parece designar a los profetas (o según Puech a los sacerdotes), y porque el paralelo en la línea 6 de רוחו ..., me parece favorecer claramente la comprensión de la palabra como un singular con el sufijo claramente referido a Dios.

Así pues, el texto trataría aquí de un solo Mesías. Pero no es fácil determinar si este personaje es el Mesías davídico $u$ otra figura mesiánica, ya que lo único que sobre él nos dice el texto es que "los cielos y la tierra le escucharán" y que en su época todo lo que hay en ellos «no se apartará de los preceptos de los santos» ${ }^{14}$. Una referencia fragmentaria a "su cetro" en la columna siguiente (fragm. 2 III 6) podría orientarnos hacia el Mesías-rey, pero por una parte la lectura es incierta y por otra no hay manera de probar que este personaje es el mismo que el Mesías de II $1{ }^{15}$. La única indicación que yo encuentro en el texto para identificar a este Mesías con el Príncipe de la congregación es que el horizonte de la salvación escatológica que el Señor realiza durante su época parece estar limitado a la congregación escatológica, la asamblea de los fieles de

${ }^{13}$ En fragm. 9,3 la palabra משיח se halla incompleta, por lo que no es utilizable.

${ }^{14}$ Una expresión única y difícil de explicar, puesto que en los demás escritos se trata siempre de los preceptos de Dios, y en la mayoría de los casos Dios aparece explícitamente mencionado. En los textos de Qumrán, como en la Biblia hebrea, "santos" puede designar obviamente a los ángeles, por lo que la frase podría significar la unión del Mesías con los santos e indicar que en la época mesiánica toda la creación observará los preceptos angélicos; pero "los santos" es igualmente empleado (sobre todo en textos de contenido escatológico, como $1 \mathrm{QM}$ y $1 \mathrm{QSb}$ ) como una designación de los miembros de la comunidad, por lo que la expresión podría comprenderse como una alusión a los preceptos divinos tal y como son interpretados por los miembros de la comunidad. ¿O se trata simplemente de una calificación objetiva de estos preceptos como preceptos santos?

${ }^{15}$ De hecho, la referencia a todo Israel, en III 5, podría implicar un contexto diferente, ya que el autor parece restringir su horizonte a los miembros fieles de la comunidad en la descripción de la edad mesiánica de la col. II. Puech reconoce en la alusión al cetro una referencia al Mesías de Israel, y en las alusiones al sacerdocio de los fragms. 8-9 una posible referencia al Mesías sacerdotal, pero concluye prudentemente: "Le contexte très lacunaire de ces passages ne permet pas de savoir si ce manuscrit est témoin de la fusion en un seul personnage de la double attente d'un messie sacerdotal et d'un messie davidique comme il est de règle à Qumrân (voir fg. 11), ou si on a affaire simplement à deux passages bien distincts traitant séparément des deux oints». E. PuECH, art. cit., pág. 487. El estado del manuscrito no permite sacar ninguna conclusión. 
los últimos tiempos. Es cierto que las fórmulas empleadas son casi todas ellas de raigambre bíblica, pero el conjunto de las promesas se limita ciertamente a los que buscan al Señor, esperan en él y perseveran en su servicio. Aunque en sí mismas estas expresiones pueden perfectamente referirse a todos los fieles de Israel, la doble mención de los "piadosos" (los hasîdîm a los que se recompensa con "el trono de la realeza eterna»), que encuadran las referencias provenientes del Sal 146, y el hecho de que una de las acciones de esta edad mesiánica sea precisamente la supresión de los obstáculos físicos que impiden formar parte de la comunidad, parece indicar que el horizonte de la salvación escatológica que el Señor realiza en la época de su Mesías se limita a los miembros de la congregación escatológica. Lo que podría indicar que en este texto la simple designación de Mesías era empleada como referencia al Mesías davídico, el Príncipe de la congregación, al que $1 \mathrm{QSb}$ presenta en estrecha relación con la congregación.

\section{2. $4 \mathrm{Q} 285$}

Como ejemplo del segundo tipo de opciones necesarias cuando la lectura es cierta, pero la frase puede interpretarse de diversas maneras, he escogido $4 \mathrm{Q} 285$, un texto aún parcialmente inédito, pero que últimamente ha recibido una gran publicidad, y que en el fragm. 5 trata de este mismo personaje, el Principe de la congregación, al que identifica con "retoño de David".

La obra de la que este fragmento proviene se ha conservado en dos ejemplares ${ }^{16}$ y era conocida como Bërakôt milhamâ, aunque es muy posible que ambas copias provengan del final perdido del Rollo de la guerra, conocido por copias de la Cueva 1 y de la Cueva 4. El

\footnotetext{
${ }^{16} 4$ Q285 y la copia proveniente de la Cueva 11 publicada por A. S. VAN DER Woude con el título "Ein neuer Segensspruch aus Qumrân (11QBer)", en Bibel und Qumrân (Festschrift H. Bardtke), Berlin 1968, págs. 253-258, que coincide con los fragmentos 3 y 4 de 4 Q285. Esta correspondencia fue señalada por J. T. MıLIK, "Milkîsedeq et Milkî-reša ' dans les anciens écrits juifs et chrétiens", JJS 23 (1972) 95-144, 143 , que fue igualmente el primero en sugerir que ambos manuscritos provienen del final perdido de la Regla de la guerra: "Malgré l'absence des recoupements, le manuscrit $4 \mathrm{Q} 285$ constitue à peu près certainement un autre exemplaire du serek hamilhamah. Les fragments conservés de ce rouleau appartenaient à la partie finale du Manuel, entièrement perdue dans 1QM; en revanche, quelques-uns de mes morceaux recoupent un très beau fragment de la Grotte 11 de Qumrân».
} 
contenido general de los fragmentos conservados, la referencia en ambos a la destrucción de los kittim, la mención de los arcángeles Gabriel y Miguel, y las alusiones al Príncipe de la congregación ", son otras tantas indicaciones en esta dirección. Sea lo que fuere sobre la identidad de ambas composiciones, lo cierto es que el fragm. 5 de $4 \mathrm{Q} 285$ es interesante para nuestro tema.

El fragmento fue dado a conocer en los periódicos en noviembre de 1991 por los Profesores R. Eisenman y M. Wise como un fragmento que contenía la muerte del Mesías, ofreciendo así un perfecto paralelo con la idea cristiana y con la posterior concepción rabínica del Mesías hijo de José, que muere en la batalla escatológica. Un artículo posterior de G. Vermes ${ }^{18}$ proporcionó el primer análisis científico del texto, al que respondió posteriormente J. D. Tabor ${ }^{19}$. El texto en cuestión puede traducirse así:

1 [... como dijo] Isaías el Profeta: serán cortados [los más gruesos del] ${ }^{2}$ [bosque con el hierro y el Líbano, con su esplendor,] caerá. Saldrá un renuevo del tocón de Jesé $[\ldots]^{3}[\ldots]$ el retoño de David, y entrarán en conflicto con $[\ldots]^{4}[\ldots]$ y le matará el Principe de la congregación, el re[toño de David ...] ${ }^{5}[\ldots]$ y con heridas. $Y$ un sacerdote ordenará $[\ldots]^{6}[\ldots]$ la destrucción de los kittim [...]. (4Q285 fragm. 5) ${ }^{20}$.

La polémica, y el motivo por el que he escogido este texto como ejemplo, se centra evidentemente en la interpretación de la línea 4 y se debe tanto al carácter fragmentario del texto como a la ambigüedad misma de la expresión hebrea empleada: והמיתו נשיא העדה. La forma hif $\hat{f} \hat{l}$ empleada puede ser vocalizada como una tercera persona plural (ellos matarán) o como una tercera persona singular con sufijo (él lo matará). El empleo de un verbo en plural en la línea 3 podría favorecer la comprensión del verbo como plural suponiendo

17 Además del fragm. 5,4, se hace referencia al Príncipe de la congregación en los fragmentos 4,2 y 6 y fragm. 6,2; pero desgraciadamente se trata de referencias demasiado fragmentarias como para aportarnos ningún elemento útil. El Príncipe de la congregación aparece también en $1 \mathrm{QM} \mathrm{V} 1$ donde únicamente se nos dice la inscripción que portará en su cetro, y en $C D$ 7,20 y 4Q376.

18 G. Vermes, "The Oxford Forum for Qumran Research Seminar on the Rule of War from Cave 4 (4Q285)", JJS 43 (1992) 85-94.

19 J. D. TABOR, "A Pierced or Piercering Messiah? - The Verdict is Still Out", $B A R$ 18/6 (1992) 58-59.

${ }^{20}$ Cf. F. Garcia Martinez, Textos de Qumrán, pág. 175. 
una continuidad entre ambas; pero la laguna existente y la presencia en la línea 5 de un verbo en singular reduce la fuerza de este argumento. Por otra parte la ausencia del indicativo de objeto delante de "Príncipe de la congregación" aconseja claramente considerar al Príncipe de la congregación como sujeto del verbo, aunque tampoco es éste un argumento decisivo. En definitiva, solo el contexto puede ayudarnos a decidir entre las dos interpetaciones gramaticalmente posibles. Pero este contexto no deja, en mi opinión, duda alguna sobre el significado de la frase.

En el texto de Isaías, que el autor cita expresamente, no se anuncia la muerte del retoño de David sino que será él expresamente quien juzgará y quien matará al impío. Aún más importante es la interpretación qumránica de este texto bíblico en 4Q161. En ella no solamente se menciona al "Príncipe de la congregación" en col. II 15 , sino que se acentúa su carácter victorioso y se interpreta «Líbano" y «los más gruesos del bosque» como significando a los kittim que son puestos en su mano (col. III 1-8). Esa misma exaltación victoriosa del Príncipe de la congregación la hemos visto en $1 \mathrm{QSb}$, que también emplea el texto de Isaías, y aparece igualmente en las demás alusiones qumránicas al personaje. De la misma manera, la referencia a «la destrucción de los kittim», de la línea 6, nos sitúa claramente en la perspectiva del Rollo de la guerra y de la victoria definitiva sobre las fuerzas del mal. Lo que nos indica que la idea de que es el Príncipe de la congregación quien mata a su adversario es la que mejor se adapta tanto al texto bíblico de origen, como a las otras interpretaciones de ese texto en los escritos qumránicos; es la que mejor explica todos los elementos conservados, y está provista de paralelos convincentes en otros textos relacionados.

La idea, por el contrario, de la muerte de este Príncipe de la congregación a manos de su adversario escatológico, no se halla documentada en ningún otro texto qumránico que trata del Mesías davídico, ni en ningún otro de los textos qumránicos que mencionan al Príncipe de la congregación; la alusión de Daniel 9,25-26 a la muerte del «ungido" o las alusiones al "siervo sufriente» de Is 40-45 no tienen ningún papel. Por lo que debemos concluir, que la muerte del Mesías es contextualmente ajena al tenor de nuestro texto. Lo que justifica la opción hecha en la traducción del mismo. 


\section{3. $4 \mathrm{Q} 246$}

Como modelo del tercer tipo de opciones, he escogido 4Q246. Algunas líneas de este texto eran conocidas desde hace bastante tiempo ${ }^{21}$ y habían sido ampliamente estudiadas ${ }^{22}$, pero la reciente publicación íntegra del fragmento ${ }^{23}$ que nos da a conocer las últimas cinco líneas de la col. II permite analizarlo de una manera más completa. Se trata del único fragmento conservado de una composición aramea, datable paleográficamente en la primera mitad del siglo I. Este fragmento proviene del final de una hoja de cuero y conserva trazas de la costura con la hoja siguiente; en él se nos ha conservado una columna completa de nueve líneas y la mitad aproximadamente de la columna precedente. El texto conservado puede traducirse así:

Col. I: ${ }^{1}[\ldots]$ se instaló sobre él y cayó ante el trono ${ }^{2}[\ldots]$ rey eterno. Tú estás airado y tus años ${ }^{3}[\ldots]$ te verán, y todo venga por siempre. ${ }^{4}[\ldots]$ grandes, la opresión vendrá sobre la tierra ${ }^{5}[\ldots]$ y grandes matanzas en la ciudad ${ }^{6}[\ldots]$ rey de Asiria y de Egipto ${ }^{7}[\ldots]$ será grande sobre la tierra ${ }^{8}[\ldots]$ harán, y todos servirán ${ }^{9}[\ldots]$ grande será llamado y será designado con su nombre.

Col. II: ${ }^{1}$ Será denominado hijo de Dios, y le llamarán hijo del Altísimo. Como las centellas ${ }^{2}$ de una visión, así será el reino de ellos; reinarán algunos años sobre ${ }^{3}$ la tierra y aplastarán todo; un pueblo aplastará a otro pueblo y una ciudad a otra ciudad, ${ }^{4}$ vacat hasta que levante

${ }^{21}$ El texto había sido presentado por J. T. Milik en una conferencia dada en la Universidad de Harvard en 1972 y fue dado a conocer por J. A. FitZMYER en su estudio "The Contribution of Qumran Aramaic to the Study of the New Testament", NTS 20 (1972-1974) 382-407, estudio reproducido con un addendum importante en J. A. Fitzmyer, A Wandering Aramean. Collected Aramaic Essays, Chico 1979, págs. 85107.

22 Ver D. Flusser, "The Hubris of the Antichrist in a Fragment from Qumran", Immanuel 10 (1980) 31-37 y F. García MARTínez, "4Q246: ¿Tipo del anticristo o libertador escatológico?», en V. Collado - E. Zurro (eds.) El Misterio de la Palabra. Homenaje a Luis Alonso Schökel, Madrid 1983, págs. 229-244 [versión inglesa "The eschatological figure of 4Q246" en F. GARCía MARTínEZ, Qumran and Apocalyptic, Leiden 1992, págs. 162-179]. El estudio de G. KUHN, «Röm 1,3 f und der davidische Messias als Gottessohn in den Qumrantexten", en Ch. BurCHARD - G. THIESSEN (eds.), Lese-Zeichen für Annelies Findeiß zum 65 Geburtstag am 15 März 1984, Heidelberg 1984, págs. 103-113, no me ha resultado accesible.

${ }^{23}$ E. PUECH, «Fragment d'une apocalypse en araméen $(4 \mathrm{Q} 246$ = pseudo-Dand $)$ et le "Royaume de Dieu"", RB 99 (1991) 98-131. 
al pueblo de Dios y haga descansar a todo de la espada. Vacat. ${ }^{5} \mathrm{Su}$ reino será un reino eterno, y todos sus caminos en la justicia; juzga[rá] ${ }^{6}$ la tierra con justicia, y todos harán la paz. Cesará la espada en la tierra, ${ }^{7}$ y todas la ciudades le rendirán homenaje. El Dios grande con su fuerza ${ }^{8}$ hará la guerra por él; pondrá los pueblos en su mano y ${ }^{9}$ arrojará todos ante él. Su dominio será un dominio eterno, y todos los abismos (4Q246) ${ }^{24}$.

Yo describía así el contenido del texto tal y como era conocido en 1983: «El texto nos habla de que alguien (¿un vidente?) cae ante el trono del un rey y se dirige a él. Le describe los males que han de venir, entre los que la referencia a Asiria y Egipto desempeña un papel importante. Aún más importante será la aparición de un personaje misterioso al que le serán dados los títulos de "hijo de Dios" e "hijo del Altísimo", personaje que "será grande sobre la tierra" y a quien "todos serviran". A su aparición seguirán tribulaciones, pero estas serán pasajeras como una centella y sólo durarán "hasta que se alce el pueblo de Dios". El resultado será el fin de la guerra, un reinado eterno en el que todos harán la paz, las ciudades estarán sumisas, porque el Dios grande estará con él (¿con su pueblo?) y le someterá a todos sus enemigos» ${ }^{25}$. Después de exponer las interpretaciones de Milik (que identificaba el personaje misterioso con Alejandro Balas), de Fitzmyer (que aplicaba los títulos a un personaje real, heredero del trono de David, pero no mesiánico) y de Flusser (que veía en este personaje misterioso una referencia al Anticristo) y los motivos por los que me parecían inadecuadas, yo proponía comprender el personaje al que el texto se refiere como un "libertador escatológico" de naturaleza angélica, es decir, no-humana, una figura semejante en cuanto a sus funciones a las que $11 \mathrm{QMelch}$ atribuye a Melquisedec $\mathrm{o} 1 \mathrm{QM}$ al Príncipe de la luz $\mathrm{o}$ al arcángel Miguel. El editor del texto completo, E. Puech, piensa que el texto conservado no permite zanjar definitivamente entre una interpretacion "historizante" como la de Milik y una interpretación mesiánica hacia la que parecen ir sus preferencias. Puech parece excluir mi interpretación por dos motivos: porque no es seguro que $4 \mathrm{Q} 246$ sea una composición de origen qumránico y porque, en su opinion, "Les figures 'célestes' que sont les médiateurs de salut dans le

${ }^{24}$ Cf. F. García Martínez, Textos de Qumrán, págs. 185-186.

${ }^{25}$ En el estudio citado en la nota 21, págs. 233-234. 
judaïsme ancien, Hénoc, Elie, Melkîsédek ou le Fils de l'Homme, n'ont pas, à proprement parler, reçu le titre de 'messie'» ${ }^{26}$. Pero esta afirmación no es, como veremos, completamente correcta, y los paralelos que yo señalaba con las ideas contenidas en otros escritos qumránicos, si no son determinantes para atribuir un origen sectario a la composición, sí la hacen al menos perfectamente compatible con el pensamiento del grupo qumránico.

Yo sigo, pues, convencido de que mi interpretación de la primera columna fragmentaria y de las cuatro primeras líneas de la col. II sigue siendo la que mejor explica los elementos conservados. $\mathrm{Mi}$ calificación del personaje en cuestión como "angélico" se fundaba en el paralelo con otras figuras no humanas de los textos qumránicos, aunque tal vez sea más correcto el designar a esta figura sobrehumana simplemente como "celeste". Y las nuevas líneas ahora disponibles confirman y acentúan, en mi opinión, esta conclusión, puesto que describen a esta figura con los rasgos del Hijo del hombre de Daniel ${ }^{27}$. Las citas de Dan 7 son especialmente notables: מלכותה מלכות עלם, de col. II 5, proviene de Dan 7,27 donde es aplicado al "pueblo de los santos del Altísimo", mientras que שלטנה שלטן עלס, de col. II 9, proviene de Dan 7,14 donde es aplicado al Hijo del hombre. En el texto bíblico el paralelismo de ambas expresiones en la visión y en su explicación podría favorecer la interpretación del Hijo del hombre como figura colectiva, pero el autor de nuestra composición parece atribuir ambas expresiones al protagonista misterioso de su relato, al que considera sin duda alguna como un individuo, precediendo así la interpretación claramente individual que encontramos en el Libro de las parábolas.

El texto conservado no excluye definitivamente el que los sufijos pronominales de tercera persona, que emplea a partir de col. II 5, puedan referirse al pueblo de Dios. De hecho, a la mayoría de expresiones empleadas se les puede encontrar equivalentes bíblicos que las refieren unas veces a un personaje individual y otras a un personaje que representa al pueblo o al pueblo mismo. Pero a pesar de esta ambigüedad, las líneas últimamente publicadas me inclinan a modificar la posición que yo había adoptado en 1983, atribuyendo

${ }^{26}$ E. PuECH, «Fragment», págs. 124-125 y pág. 102, nota 14.

${ }^{27}$ Sobre la interpretación del Hijo del hombre de Dan 7 como un individuo de naturaleza angélica, ver J. J. Collins, The Apocalyptic Vision of the Book of Daniel, Ann Arbor 1977, págs. 144-147. 
estos pronombres al pueblo de Dios, y a adoptar la interpretación de Puech, que los refiere claramente al protagonista mencionado al final de la col. I y al comienzo de la col. II.

La indicación de Puech de que en col. Il 4, puede leerse יקים 'él levante' en vez de יקום 'se alce (el pueblo)', y יניח 'él hará descansar todo' en lugar de ינוח 'todo descansará', permite comprender esta línea 4 como la culminación del período de crisis descrito precedentemente, permite comprender los títulos excelsos que se dan al protagonista, puesto que la tarea que él deberá cumplir es la de introducir la situación de paz escatológica, y permite dar a la partícula ע su valor de término ${ }^{28}$. Esta interpretación se halla reforzada por el empleo en la col. II 5, de [1] יד' 'él juzgará', lo mismo que por la afirmación de la dimensión cósmica de su reinado de col. II 9.

Esta lectura del texto se halla reforzada por la manera en que la frase en cuestión esta dispuesta en el manuscrito. El vacat que precede a la mención del "pueblo de Dios" parece destinado a realzar que esta situación de paz escatológica es precisamente la conclusión de la situación previamente descrita y que se debe a la actuación del protagonista al que se han dado los títulos excelsos de "hijo de Dios" e "hijo del Altísimo". El vacat que en la misma línea sigue a esta expresión suprime la necesidad de referir al antecedente más próximo ("el pueblo de Dios», el objeto de la frase precedente) toda la serie de sufijos de las líneas siguientes, y permite el referirlos al sujeto de la frase, el «hijo de Dios" e "hijo del Altísimo".

Comprendido de esta manera, 4Q246 nos describe un libertador escatológico de naturaleza celeste semejante al Hijo del hombre de Dan 7, al que designa como "hijo de Dios" e «hijo del Altísimo", personaje que será el agente que introducirá la salvación escatológica, juzgará a toda la tierra, vencerá a todos los reyes por la fuerza de Dios y dominará sobre el universo entero. Es decir, nos describe una figura que podemos designar como un mesías celeste. Este título puede causar extrañeza y puede incluso parecer contradictorio. El que en el judaísmo de la época pudiera haberse desarrollado la esperanza de un agente de salvación escatológico de naturaleza sobrehumana es algo perfectamente comprensible; el que a éste agente de salvación escatológica lo consideremos como un Mesías

28 Ver E. PuECH, «Fragment», págs. 116-117. 
puede parecer no sólo una ampliación ilegítima del concepto de Mesías sino una ampliación que vacía el concepto de Mesías de su característica más profunda, su dimensión humana. No sólo resulta difícil el imaginar la posibilidad de que a un personaje sobrehumano se le considere como "ungido" (los ángeles ciertamente no reciben la unción), sino que la naturaleza humana de todos los otros Mesías que encontramos en Qumrán se halla fuertemente acentuada: en la descendencia davídica del Mesías-rey, y en la perspectiva cultual en la que el Mesías-sacerdote realiza su expiación. Si además se tiene en cuenta que en el texto en cuestión el término técnico "ungido" no aparece, el intento de considerarlo como "mesiánico" puede parecer como algo artificial y la ampliación semántica del término Mesías que ella implica como carente de sentido.

$\mathrm{Y}$ sin embargo me parece difícil evitar el empleo del adjetivo mesiánico para caracterizar al protagonista de este texto, puesto que las funciones que se le atribuyen son realmente funciones mesiánicas. El hecho de que otros escritos judíos no qumránicos que describen un agente de salvación escatológico de naturaleza sobrehumana empleen el término técnico de Mesías como una de las designaciones de la figura salvadora que describen, prueba, en mi opinión, que la ampliación del campo semantico de "Mesías se había ya realizado en el judaísmo de la época y nos obliga a no excluir a priori esos textos, bajo pena de ignorar uno de los posibles desarrollos de la esperanza mesiánica reflejados en los manuscritos que se han conservado. Los textos a los que me refiero son, evidentemente, Las parábolas de Henoch y el IV Esdras. El primero emplea ocasionalmente el término Mesías (en 48,10 y 52,4) junto con las designaciones más comunes de "Elegido" y sobre todo de "Hijo del hombre" ${ }^{29}$ para designar a una figura preexistente, transcendente y de origen celeste. En la visión incorporada por el autor del $I V$ Esdras en el cap. 13 un personaje "como un hombre", al que se designa en 7,28 y en 12,32 como "Mesías" y más frecuentemente como «hijo/siervo de Dios", es presentado claramente como un personaje igualmente

${ }^{29}$ Ver J. C. VanderKam, «Righteous One, Messiah, Chose One, and Son of Man in 1 Enoch 37-71", en J. H. ChARLesworTh (ed.), The Messiah. Developments in Earliest Judaism and Christianity, Minneapolis 1992, págs. 169-191, con referencia a los estudios precedentes. 
preexistente, transcendente y de origen celeste ${ }^{30}$. Ambas figuras son designadas en estos textos como Mesías a pesar de su carácter sobrehumano y de ser descritas con imágenes tradicionalmente asociadas con la divinidad, por lo que, como atinadamente observa J. J. Collins "1, "the understanding of 'messiah' is thereby qualified". Estos paralelos en dos composiciones, cuyo origen judío hoy no parece ser puesto en duda, justifican la interpretación general aquí adoptada. Y aunque nuestro texto no emplea la palabra Mesías para designarlo, este término sí aparece en otro de los textos qumránicos ya conocidos desde antiguo, 11QMelch, en el que a este mismo tipo de figura salvadora de naturaleza sobrehumana, que ejecuta el juicio divino, libera del poder de Belial y rescata a los hombres de su lote en la primera semana del último jubileo de la historia, no sólo se le llama 'elohîm sino "ungido del espíritu", claramente en singular משיח הרוח.

Como han podido comprobar con estos tres ejemplos, las traducciones ofrecidas en Textos de Qumrán son, frecuentemente, el resultado final de un largo proceso en el que las opciones de lectura del texto consonántico, las opciones de interpretación de expresiones gramaticalmente polivalentes, y las opciones del sentido general de un texto en función del contexto más amplio que proporcionan los otros manuscritos procedentes de la misma biblioteca, desempeñan un papel muy importante. Evidentemente, todas estas opciones son discutibles, y las que yo he hecho serán seguramene discutidas. Pero, puesto que estas opciones son el fruto de un profundo respeto por esos Textos de Qumrán, espero que terminarán contribuyendo a un mejor conocimiento de los mismos.

FLORENTINO GARCÍA MARTÍNEZ Qumrân Instituut. Universidad de Groningen

\footnotetext{
${ }^{30}$ M. STONE, "The Question of the Messiah in 4 Ezra" en ÍDEM, Selected Studies in Pseudepigrapha \& Apocrypha, Leiden 1991, 317-332 [= J. NEuSNER - W. S. GREEN - E. Frerichs (eds.), Judaisms and Their Messiahs at the Turn of the Christian Era, Cambridge 1987, págs. 209-224] y “Excursus on the Redeemer Figure» en M. STONE, Fourth Ezra, Minneapolis 1990, págs. 207-213.

${ }^{31}$ En un excelente artículo en el que subraya cómo ambas figuras representan una determinada interpretación mesiánica de Daniel 7, «The Son of Man in First-Century Judaism", NTS 38 (1992) 448-466. El mismo J. J. Collins (pág. 466, nota 78) sugiere que $4 \mathrm{Q} 246$ podría contener una semejante interpretación mesiánica de la figura daniélica, una intuición que me parece completamente correcta y conforme a mi compresión del texto.
} 